\title{
Young Women Sexual Behaviour and Self-Reported Sexually Transmitted Diseases in Northern Ethiopia: A Cross Sectional Study
}

\author{
Girmatsion Fisseha ${ }^{1, *}$, Endeshaw Admassu ${ }^{2}$ \\ ${ }^{1}$ Mekelle University, College of Health Sciences, Department of Public Health, Mekelle, Ethiopia \\ ${ }^{2}$ Gondar University, Colege of Medical Science, Department of Midwifery, Gondar, Ethiopia
}

Email address:

girmaf4@yahoo.com (G. Fesseha), endeshaw_99@yahoo.com (E. Admassu)

\section{To cite this article:}

Girmatsion Fisseha, Endeshaw Admassu. Young Women Sexual Behaviour and Self-Reported Sexually Transmitted Diseases in Northern Ethiopia: A Cross Sectional Study. European Journal of Preventive Medicine. Vol. 3, No. 3, 2015, pp. 55-62.

doi: 10.11648/j.ejpm.20150303.14

\begin{abstract}
Background: Globally, sexually transmitted diseases (STDs) remain a significant public health problem especially among young women. In Ethiopia, the prevalence of STDs among femal youths aged 15-24 years old continues to be a problem of young population. However, the factors associated with this problem is poorly studied. Thus, the purpose of this study is to assess sexual behavior and prevalence of STDs and factors associated among young women attending health facilities in Northern Ethiopia. Methods: A Facility-based cross-sectional study was employed among 326 young women aged 15 to 24 years from May 1 to 30, 2013. A multistage sampling technique was used to select young women attending outpatient facility. A pre-tested interviewer guided structured questionnaire was used for data collection. Data was entered, cleaned and analyzed using SPSS version 20.0. Bivariate and multivariate logistics regression analyses were done to identify the associated variables. A p-value of 0.05 with $95 \% \mathrm{CI}$ were used as a cutoff point to examine the statistical association. Results: From the total of 326 sample, 305 young women were participated in this study with a response rate of $93.6 \%$. The median age at first sex was 17 years (range 9-24 years). The prevalence of self-reported STDs in the last 12 months preceding the survey was $21.3 \%$. One hundred fourteen $(40.4 \%)$ of the young women had poor knowledge on STDs mode of transmission and prevention. Having two or more sex partners, not using condoms, poor knowledge on STDs mode of transimission and prevention, and a previous history of STDs were found to be significantly associated with self reported STDs. Conclusions: In this study the sexual behavior, not using condom and prevalence of STD was found to be high. Many young women had started early sexual contact and have poor utilization of condom. Hence, the youth friendly services, partner treatment and life skill communication with parents should be enhanced through the joint effort of all concerned stakeholders.
\end{abstract}

Keywords: Sexual Behaviour, Self-reported STDs, Young woman, Northern Ethiopia

\section{Introduction}

Early sexual behavior and sexually transmitted diseases (STDs) remain a major public health problem worldwide. According to World Health organization (WHO) 2008 estimates, about 498.9 million new cases of curable STDs occurred among men and women aged 15-49 years. About 384.4 million STDs cases occurred in Africa with 92.6 million new cases in 2008 [1].

Young women are often at a higher risk of acquiring STDs due to different reasons, such as inability to conceptualize actions, their physiologic susceptibility, peer pressure and economic issues. The risk is higher among socially and economically marginalized young people and bi. In addition, sexually active girls are at higher risk of contracting STDs than boys for biological reasons [2-5].

STDs caused by chlamidal and gonerial infection mainly increases the risk of HIV transmission 5 to 10 times and cause long term squeal including infertility, tubal pregnancy, chronic pain in the pelvis, cervical cancer, fetal and prenatal health problems [6]. The economic cost is high. In developing countries, STDs caused disability accounts for $17 \%$ of economic losses [7].

In sub-Saharan African countries, the STDs case burden is very high. It is estimated that $80-90 \%$ of the global burden of STDs found in the developing world where there is limited or 
no access to diagnostics [8]. In spite of the high prevalence of STDs in the region, relatively little epidemiological research has been carried out on their prevalence and incidence [9].

In Ethiopia, despite the large scale up of health care investments in prevention and treatment of STDs [10], the prevalence continues to be a youths' problem. STD prevalence among youth women in Ethiopia increases from $2.9 \%$ in 2005 to $3.6 \%$ in 2011 [11, 12]. In addition, Ministry of Health had compiled 113,386 and 104,607 STD cases during 2011 and 2012 in the country [13]. This revealed that STDs are underreported in Ethiopia [9]. Besides this there are limited studies in the country in assessing sexual behavior and STDs prevalence. Furthermore, studies targeting young women are very rare in Ethiopia. Therefore, the purpose of this study is to assess the magnitude of sexual behavior and factors associated with STDs among young women. This study may helps in enhancing the prevention and control of STDs programs in the country.

\section{Methods}

\subsection{Study Setting}

This study was conducted in Tigray from May 1 to May 30, 2013, northern Ethiopia. It is about 1017 kilometers far from the capital city of Ethiopia, Addis Ababa. The region is divided into 6 administrative zones and one special zone (Mekelle zone). In Tigray, there are about 16 governmental hospitals, 2 private hospitals and 256 health centers [14]. In the Central zone there are three hospitals and 57 health centers. Health coverage of the zone has reached $85 \%$.

\subsection{Study Design and Sampling}

Health facility based cross-sectional study design was employed. A total of 326 young women age from 15 to 24 years who visited the selected health facilities and had a boyfriend or husband during the study period were included in this study. Multistage sampling technique was used to select the young women.

\subsection{Measurements}

Data was collected using a pretested semi-structured quetionnaire $[11,15]$. The questionnaire includes variables on socio-demographic, reproductive, sexual behaviors and STDs related Knowledge's. The instrument was first prepared in English and then translated to the local language Tigrigna to make it easily understandable and reduce language inconsistencies between the data collectors and young women. A trained ten female nurses as data collectors were used. The pretest was done in 15 young women in a health center which was not included in the study. The data were collected from youth out patient department (OPD) in the health facilities with a separated youths' service which give service for greater than ten young women a day. The quality of the data was assured through careful design, translation and back translation of the questionnaire, pre-test, cleaning of data. And the data collection was carried out under intensive supervision. The principal investigator has been also examining the collected data for completeness and consistency.

\subsection{Statistical Analysis}

The outcome variable of this study was sexual behavior and STD among young women which categorical variable (STD yes/no) and categorical data analysis method is used. The collected data were edited, coded, entered, cleaned and analyzed using SPSS software version 20 statistiscal package.

Descriptive analysis: like percentage, frequencies, median, mean, standard deviation, table and graphs were used. The prevalence was estimated in the last 12 months preceding the study period. According to the standard management of STDs, a youth considered as acquired STDs if she has at least one of the six STD signs and symptoms like lower abdominal pain, genital ulcer or sore, vaginal discharge, burning sensation during urination, itching sensation on the genitalia and swelling in the groin in the last 12 months, the youth was considered having a STDs. Knowledge of young women on STD was assessed using 12 items question, which contains question about STDs awareness, mode of transmission and prevention, and aware of misconception about STDs prevention. If young women answer at least eight items correctly she was considered as she had good knowledge unless clasified as she had poor knoweldge.

Bivariate logistic regression was done to analyze the possible risk factors associated to STDs. Multiple logistic regression was performed to identify the most significant predictor of STD and to control for confounders. Multicollinearity test was also done. Odds ratio and confidence interval with $95 \%$ confidence limits and significance level $(p<0.05)$ were used to determine their level of significance.

\subsection{Ethical Consideration}

Ethical clearance was obtained from Mekelle University Ethics Review Board. Letter of support was obtained from the Tigray Regional Health Bureau. Moreover, an informed written consent was obtained from all study participants. The participants were informed about the purpose study. They were also told they had right to discontinue or refuse to participate in the study any time they wanted to. Confidentiality and privacy were maintained.

\subsection{Socio-Demographic Characteristics}

A total of 305 young women were participated in this study giving a response rate of $96.3 \%$. Nearly two third of the young women $(66.2 \%)$ were from urban residence, and most of them $225(73.8 \%)$ were found in the age group between 20 to 24 years. The median age of the young women was 21 years (range 15-24 years). More than ninety percent of the young women $279(91.5 \%)$ were Orthodox Christian and almost all 299(98\%) were Tigrayean in ethnicity. Predominate education level of the young women was secondary $115(37.7 \%)$. Most of young women 93(30.5\%) were students (Table 1). 
Table 1. Socio-demographic characteristics of young women in Northern Ethiopia, 2013.

\begin{tabular}{|c|c|c|}
\hline Socio demographic Variables & No & $(\%)$ \\
\hline \multicolumn{3}{|l|}{ Residence } \\
\hline Urban & 202 & 66.2 \\
\hline Rural & 103 & 33.8 \\
\hline \multicolumn{3}{|l|}{ Age of respondent } \\
\hline $15-19$ & 80 & 26.2 \\
\hline $20-24$ & 225 & 73.8 \\
\hline \multicolumn{3}{|l|}{ Religion of respondent } \\
\hline Orthodox & 279 & 91.5 \\
\hline Muslim & 22 & 7.2 \\
\hline Other* & 4 & 1.3 \\
\hline \multicolumn{3}{|l|}{ Ethnic group } \\
\hline Tigray & 299 & 98 \\
\hline Other** & 6 & 2 \\
\hline \multicolumn{3}{|l|}{ Education level } \\
\hline No education & 28 & 9.2 \\
\hline Primary & 71 & 23.3 \\
\hline Secondary & 115 & 37.7 \\
\hline Above secondary & 91 & 29.8 \\
\hline \multicolumn{3}{|l|}{ With whom they lived } \\
\hline Alone & 75 & 24.6 \\
\hline Parents /relatives & 110 & 36.1 \\
\hline Husband/steady partner & 120 & 39.3 \\
\hline \multicolumn{3}{|l|}{ Occupation } \\
\hline Student & 93 & 30.5 \\
\hline Unemployed & 39 & 12.8 \\
\hline Small trade & 40 & 13.1 \\
\hline Daily labor & 37 & 12.1 \\
\hline House wife & 43 & 14.1 \\
\hline Commercial sex worker & 5 & 1.6 \\
\hline House servant & 24 & 7.9 \\
\hline Government employee & 24 & 7.9 \\
\hline
\end{tabular}

Table 2. Sexual behaviour of young women in Northern Ethiopia, 2013.

\begin{tabular}{|c|c|c|}
\hline Sexual relationship of young women & NO & $\%$ \\
\hline \multicolumn{3}{|l|}{ Marital status } \\
\hline Married /cohabiting partner & 155 & 50.8 \\
\hline Boyfriend & 135 & 44.2 \\
\hline Divorced/widowed & 15 & 4.9 \\
\hline \multicolumn{3}{|l|}{ Partners living condition } \\
\hline Living with her now & 162 & 70.1 \\
\hline Living elsewhere & 69 & 29.9 \\
\hline \multicolumn{3}{|l|}{ Age at first sexual intercourse } \\
\hline$<=14$ & 30 & 9.8 \\
\hline $15-19$ & 217 & 71.1 \\
\hline $20-24$ & 58 & 19 \\
\hline \multicolumn{3}{|l|}{ Age of the last male partner } \\
\hline $15-24$ & 95 & 31.1 \\
\hline $25-34$ & 154 & 50.5 \\
\hline $35-44$ & 39 & 12.8 \\
\hline$>45$ & 17 & 5.6 \\
\hline \multicolumn{3}{|c|}{ Number of sexual partner in the last 12 months } \\
\hline One & 278 & 91.1 \\
\hline Greater or equal to two & 27 & 8.9 \\
\hline \multicolumn{3}{|l|}{ Relationship to the last sexual partner } \\
\hline Husband /cohabiting partner & 155 & 50.8 \\
\hline Boyfriend & 76 & 24.6 \\
\hline Casual acquaintance & 74 & 14.3 \\
\hline \multicolumn{3}{|l|}{ Number of sexual partner in life time } \\
\hline One & 254 & 83.3 \\
\hline Greater or equal to two & 51 & 16.7 \\
\hline \multicolumn{3}{|l|}{ Last sexual intercourse } \\
\hline Voluntary & 268 & 87.9 \\
\hline Forced & 19 & 6.2 \\
\hline For favor/cheating & 18 & 5.9 \\
\hline
\end{tabular}

Other*:Catholic and protestant

Other**: Amara and Oromo

$\mathrm{N}=305$

Table 3. Behavioral characteristics of young women in the last 12 months in Northern Ethiopia, 2013.

\begin{tabular}{|c|c|c|}
\hline Behavioral characteriSTDes of young women & No & (\%) \\
\hline \multicolumn{3}{|l|}{ Frequency of watching pornography $(\mathrm{n}=305)$} \\
\hline Not at all & 238 & 78 \\
\hline Ever watched & 67 & 22 \\
\hline \multicolumn{3}{|c|}{ Drink alcohol in the last sexual intercourse with the last partner $(n=305)$} \\
\hline Neither partner nor respondent & 239 & 78.4 \\
\hline Both partner and respondent & 66 & 21.6 \\
\hline \multicolumn{3}{|c|}{ Last partner used Condom after drinking alcohol(n=66) } \\
\hline No & 49 & 74.2 \\
\hline Yes & 17 & 25.8 \\
\hline \multicolumn{3}{|l|}{ Chew chat in the last sexual intecourse $(n=305)$} \\
\hline Partner or respondent & 12 & 3.9 \\
\hline Neither & 293 & 96.1 \\
\hline \multicolumn{3}{|c|}{ Condom used during the last SI with the last partner $(\mathrm{n}=305)$} \\
\hline No & 54 & 36.2 \\
\hline Yes & 95 & 63.8 \\
\hline \multicolumn{3}{|l|}{ Ever used condom $(\mathrm{n}=305)$} \\
\hline No & 156 & 51 \\
\hline Yes & 149 & 48.9 \\
\hline \multicolumn{3}{|l|}{ Consistently condom used(n=149) } \\
\hline No & 117 & 78.5 \\
\hline Yes & 32 & 21.5 \\
\hline \multicolumn{3}{|l|}{ Ever heard of STD $(n=305)$} \\
\hline No & 23 & 7.5 \\
\hline Yes & 282 & 92.5 \\
\hline
\end{tabular}


Table 4. Factors associated with Sexualy transmitted diseases among young women in the last 12 months in Northern Ethiopia, 2013.

\begin{tabular}{|c|c|c|c|c|}
\hline \multirow{2}{*}{ Young women factors } & \multicolumn{2}{|c|}{ Self-reported STD } & \multirow{2}{*}{$\operatorname{AOR}(95 \% C I)$} & \multirow{2}{*}{ p-value } \\
\hline & No & Yes & & \\
\hline \multicolumn{5}{|l|}{ Number of partner in life } \\
\hline One & $220(86.6 \%)$ & $34(13.4 \%)$ & - & 1 \\
\hline Greater or equal to two & $20(39.2 \%)$ & $31(60.8 \%)$ & $21(7.402-61.529)$ & $0.000^{* *}$ \\
\hline Ever used condom & & & $5.27(2.016-13.754)$ & \\
\hline No & $110(70.5 \%)$ & $46(29.5 \%)$ & & $0.001 * *$ \\
\hline Yes & $149(87.2 \%)$ & $19(12.8 \%)$ & & 1 \\
\hline \multicolumn{5}{|c|}{ Knowledge on Sign and symptom of STD } \\
\hline Not know & $20(51.3 \%)$ & $19(48.7 \%)$ & $40.3(9.789-165.893)$ & $0.000^{* *}$ \\
\hline Know one sign & $85(72.6 \%)$ & $32(27.4 \%)$ & $10.65(3.447-32.919)$ & $0.000^{* *}$ \\
\hline Know two and above & $118(93.7 \%)$ & $8(6.3 \%)$ & - & 1 \\
\hline \multicolumn{5}{|c|}{ Misconception on STD prevention } \\
\hline No & $210(82.7 \%)$ & $44(17.3 \%)$ & - & 1 \\
\hline Yes & $13(46.4 \%)$ & $24(53.6 \%)$ & $11.99(3.711-38.719)$ & $0.000^{* *}$ \\
\hline \multicolumn{5}{|l|}{ Ever had STD (life time) } \\
\hline No & $209(86 \%)$ & $34(14 \%)$ & - & 1 \\
\hline Yes & $31(50 \%)$ & $31(50 \%)$ & $8.45(3.117-22.924)$ & $0.000 * *$ \\
\hline
\end{tabular}

*=significance $\mathrm{p}$-value $<0.05$

$* *=$ highly significant $\mathrm{p}$-value $<0.001$

\subsection{Sexual Relationship of Young Women}

Majority of the young women 217(71.1\%) had experienced their first sexual intercourse between the age of 15 and 19 years. The median age at first sexual intercourse was 17 years (range 9-24 years). Of the total young women, $27(8.9 \%)$ had two and more sexual partners in the last 12 months and 51(16.7\%) had two and more sexual partners in their life time. Regarding the sexual relationship, almost half of the young women $155(50.5 \%)$ were married and about one fourth of the young women had boyfriend. Regarding their last sexual intercourse, 19(6.2\%) young women were forced and $18(5.9 \%)$ were for cheated, favor and money (Table 2).

\subsection{Sexual Behavioral of the Young Women}

During the last 12 months, 67(22\%) young women reported that they had watched pornography. Sixty six (21.6\%) young women reported that they drank alcohol during the last sexual intercourse, of which $49(78.6 \%)$ did not use condom during their sexual intercourse. Similarly, 12 (3.6\%) young women reported that they chew chat. Among the total young women, $149(48.9 \%)$ ever used condom. Of those young women who ever used condom, 95 (63.8\%) used condom in the last sexual intercourse and $32(21.7 \%)$ consistently used condom (Table 3 ).

\subsection{Knowledge of Young Women about Mode of Transmission and Prevention of STDs}

Most of young women $282(92.5 \%)$ had heard about STDs. About 114(40.4\%) young women had poor knowledge on STDs mode of transmission and prevention. About 72(23.6\%) young women were not aware of method of STDs transmission (at least one). The predominant mode of transmission mentioned by the young women was unprotected sex 249(88.3\%). Regarding prevention of STD, $119(39 \%)$ young women were not aware of at least one method of STD prevention. The predominant prevention method mentioned by the young women was being faithful 199(70.6\%). About 28(9.9\%) young women had misconceptions about prevention methods of STDs. Seventy three percent of the young women knew at least one place where they could get condoms with majority $194(82.7 \%)$ of themmentioned public health institution as a predominat place for condom distributionMajority of the young women $197(64.6 \%)$ reported that they had not convinced their partner to use condom even though they had the interest to use condom during sexual intercourse.

\subsection{Prevalence of Self-Reported Sexual Transmitted Diseases Among Young Women}

Of the 305 young women, 65(21.3\%) young women reported that they had at least one STD signs and symptoms in the last 12 months. Of those who had signs and symptoms of STD in the last 12 months, 42(13.8\%) reported that they had bad smelling and abnormal discharge, $18(5.9 \%)$ vaginal discharge, $12(3.9 \%)$ genital ulcer and abdominal pain, $21(6.9 \%)$ genital itching and $5(2 \%)$ had swelling in the inguinal area. Regarding treatment of the symptoms, $35(53.8 \%)$ young women reported that they had seek treatment for their symptoms and most were treated at health center $15(42.9 \%)$ and hospital $13(37.1 \%)$. Seven (20\%) young women were self-treated from pharmaceutical drug vendors and $2(5.9 \%)$ were treated by traditional practitioners (Figure 1). 


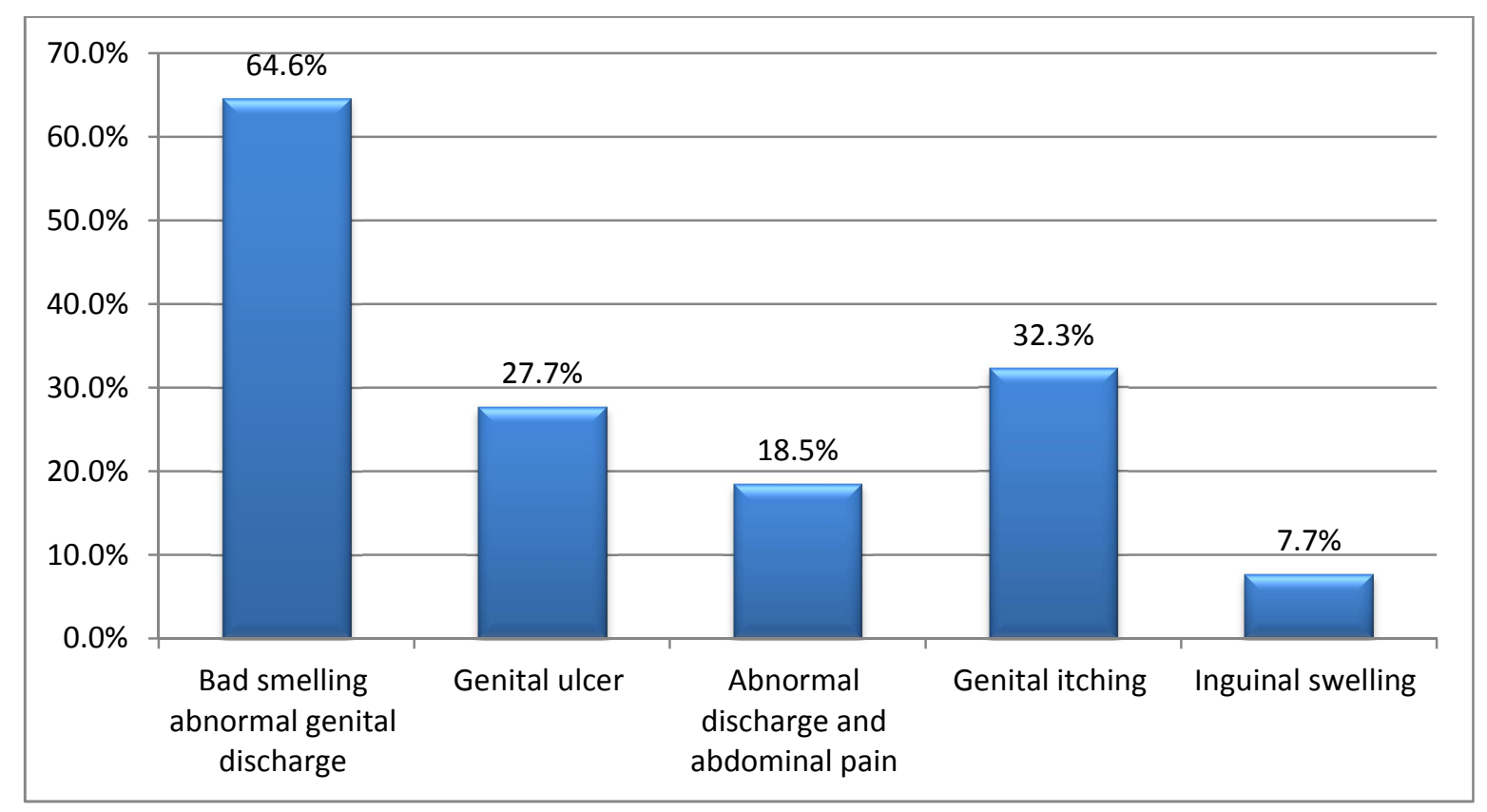

Figure 1. Distribution of STD signs and symptoms in the last 12 months among 15-24 years old young women in Northern Ethiopia, 2013.

\subsection{Factors Associated with Sexually Transmitted Diseases Among Youth in Last 12 Months}

The bivariate analysis result revealed that housewives and house servant by occupation, having male partner with more than 10 years difference in age, separated young women, 1519 years of age at start of first sexual intercourse, having more than one partner in the last 12 months, watching pornographic materials, not use condom, poor knowledge about STD transmission and prevention, poor awareness about the signs and symptoms of STD, misconception about STD transmission found to have significant association with STDs.

After adjusting for all variables that were significant at bivariate analysis, multivariate analysis revealed that having a number of partner in lifetime, not use condom, poor knowledge on signs and symptoms of STDs, having misconception on STDs prevention and previous history of STDs had found to have significantly associated with STDs.

Young women who had two and more partners in life time had higher odds of experiencing STD compared to those with one partner $(\mathrm{AOR}=8.105$; [95\% CI: 2.872, 22.875]). Women who had never used condom had higher odds of experiencing STD than those who had ever used condom (AOR=7.284; [95\%CI: 2.719, 19.513]). Young women who were not aware of signs and symptoms of STD were more likely to have STD than those who were aware of signs and symptoms of STD who mentioned two and above $(\mathrm{COR}=40.3$ [95\%CI: 9.789, 165.893]). Respondents who were aware of one signs and symptoms of STD were more likely to have STD than those who were aware of two and above signs and symptoms of STDs $(\mathrm{COR}=10.65$ [95\%CI: 3.447, 32.919]). Having previous history of STD was eight times likely to have STD than those who did not have $(\mathrm{AOR}=8.45[95 \% \mathrm{CI}$ : 3.117, 22.924]) (Table 4).

\section{Discussion}

In this study we have found a high sexual behavior and prevalence of STDs among young women. The multivariate analysis has revealed that having a number of partners in a lifetime, not use condoms, poor knowledge of signs and symptoms of STDs, having misconception on STDs prevention and previous history of STDs were positively associated with STD.

The prevalence of STDs in the last 12 months among young women is concordant with studies conducted among University students of Welaita Sodo University (19.5\%) and finding from Ghana $(21 \%)$. However, It is slightly lower than studies conducted in Debrebrhan University (28\%) and Uganda (24.3\%) [16-19]. This could be attributable to a difference in age in which the young women in the Universities were adult women greater than and equal to 20 years. Though, the prevalence is considered to be higher because the young women recruited for the study were from the health facilities where there is a high probability to find suspected cases.

The finding from this study is higher when compared with the 2011 EDHS report and school based study conducted in Addis Ababa [11, 20]. The reasons for this can be 1) the young women recruited in our study were from health facilities that the probability of including cases seeking treatment is higher, 2) the EDHS survey was population based in which most interviewed young women could be healthy and 3) unlike the study conducted in Addis Ababa, this study had included only sexually active young women and excluded non-sexually active young women. Furthermore, presence of University and colleges around the study area may be one of the reasons because high prevalence of STD has been revealed among University 
students $[16,17]$.

This study has revealed lower condom use compared to a study conducted in northeast Ethiopia [21]. This may be due to a difference in the socioeconomic characteristics of the respondent and differentiate in infrastructures.

In our study, some young women had misconception regarding mode of transmission and prevention of STD. Of the young women that had misconception, more than half have developed signs and symptoms of STD. This is consistent with a study conducted in Southern Ethiopia and South Africa, $[16,22]$. This may be due to the fact that youth's misconception may result in unprotected sexual intercourse with infected individual that may acquire an STD

A study conducted in Welaita University showed that the students had a good knowledge and $64 \%$ of the students had poor knowledge on STD transmission and prevention [16]. But in our study, about $40.4 \%$ young women had poor knowledge which is higher. This might be due to health institution based study, in which respondents may have has better contact and got information from health professionals that may increase their knowledge on the symptoms. In this study, about $28.9 \%$ of young women who had poor knowledge, had signs and symptom of STDs. This rate is higher compared with studies conducted in Welaita University, where $15.4 \%$ had STD among the students who had poor knowledge [16].

Respondents who did not know at least two symptoms of STD in this study were $55.3 \%$. It is higher compared with study conducted in Addis Ababa high school adolescents, where $17.9 \%$ of the youths had knowledge of at least two symptoms of STDs [20]. Health institution based study may have caused such difference because youths who came to health institution may have accessed to information on STD from health providers.

In our study, about $17 \%$ young women had above one sexual partner in a lifetime. Of those who had above one partner in life time, $60.8 \%$ had recent signs and symptoms of STD compared to those who had one partner (13.4\%). This is lower compared to a study conducted among University students $(52.6 \%)$ and among private college students (35\%) [23]. This may be due to the difference in socio-demographic characteristics, study area and study populations. This study has also identified $51.1 \%$ young women had never used condom. Of these who had never used condom, 30\% had signs and symptoms of STDs compared to those who had ever used condom (12.8\%). This is inline with a study conducted at Wolaita Sodo University, where ever not used condom (47.4\%) [16].

In this study, multivariate analysis revealed that young women who had two and more partners in a lifetime were more likely to have STDs than young women who had one partner $(\mathrm{AOR}=21 \quad[95 \% \mathrm{CI}: 7.402,61.529])$. Which is consistent with studies conducted at Wolaita Sodo University, where students who had multiple sexual in the life time were more than three times likely ( $\mathrm{AOR}=3[95 \% \mathrm{CI}: 1.3,6.8]$ ) to acquire an STD than those who had one partner [16]. In addition, a study in New York City showed women who reported having more than one partner were 4 times more likely to acquire STD [23].

Students with poor knowledge of STD mode of transmition and prevention were two $(\mathrm{AOR}=2.5$ [95\% CI: 1.4, 4.4]) more likely to have STDs than students with good knowledge [16]. Likewise, young women who had misconception about the transmission and prevention of STDs were 12 times likely to have signs and symptoms of STDs than their counterparts (AOR=11. 99 [95\%CI: 3.711, 38.719]). And those young women who did not identify one sign and symptom of STD were also more likely to experience signs and symptoms of STD compared to those who identified two and above signs and symptoms $(\mathrm{AOR}=40$. 3 [95\%CI: 9.789, 165.893]). This finding is in line with the fact that people who are more knowledgeable could take care of STD infection, as they are aware of both the transmission and prevention methods [24].

Young women who never used condom during intercourse were more likely to develop signs and symptoms of STD compared to their counterparts (AOR $=5.27$ [CI: 2.016, 13.754]). This is consistent with a study conducted in South Ethiopia students who never used condom during intercourse in their lifetime had increased odds of having STDs (16). Young women who had a history of STD were more likely to develop STD compared to those who who did not have STD $(\mathrm{AOR}=8.45$ [95\%CI: 3.117, 22.924]). This can be due to relapse, not treating partner, re-infection, and attributable to drug resistance or poor treatment.

As a limitation of this study, since sexual behavior is sensitive issue, under reporting is possibel. In addition, STD is assessed only through the report of young women, no physical examination was done. So, under reporting or over reporting of STDs may be also possible. Therefore, any interpretation of this finding within these variables shall take into account. The strength of this study is the use of measurement of DHS, which enabled to make the comparison of findings with other national and international literatures to be valid. And prior to conducting this study all health institutions in the study area were assessed whether they had OPD services.

\section{Conclusion}

Early sexual contact age of 17 years, poor utilization of condom and having many male partners were the main problems of youths. The prevalence of self-reported STD in the last 12 months has found to be higher as compared to the global and national level. The predominant self-reported signs and symptoms of STD in the study area were vaginal discharge. Youths in the study area had low knowledge on STD transmission and prevention. In addition, misconceptions about prevention of STD were one of the worst problems among the young women. Having multiple sexual partners in lifetime, low awareness of at least two clinical features of STDs, having misconception on the mode of transmission and prevention of STD and having a previous history of STD were found to be positive predictors of self- 
reported STDs. To solve the problem multiple approaches should be needed. Working with health sector and education sector in order to address school young women and to improve the knowledge of young women on STD and avoid misconceptions on the mode of transmission and prevention. Establishing and strengthening youth friendly services and promote referrals of STD cases are also mandatory. In addition, To address the out school young women, repeated community conversation programs, use of local media like FM radio, distributing leaflets should be designed to the level of young women.

\section{Acknowledgements}

We acknowledge the Tigray Regional Health Bureau and Mekelle University, College of Health Science for Financial assistance. We extend our deepest gratitude to managers of all health facilities for facilitating good conditions to carry out the study. Last, but not least, we thank the study young women who share their priceless time, supervisors, and the data collectors for their full commitment and technical support.

\section{Authors' Contributions}

$\mathrm{GF}^{1}$ : $\mathrm{EA}^{2}$ has took a principal role in the conception of ideas, designed the study, performed analysis and interpretation of data and critically reviewed the manuscript. All authors read and approved the final manuscript.

\section{References}

[1] World Health Organization. Global incidence and prevalence of selected curable sexually transmitted infections - 2008 . World Health Organization 2012.

[2] Department of Reproductive Health and Research. Global strategy for the prevention and control of sexually transmitted infections: 2006 - 2015. Breaking the chain of transmission. World Health Organization, 2007. /www.advocatesforyouth.org/publications/456?task=view/

[3] Sieving RE, Bernat DH, Resnick MD, Oliphant J, Pettingell $\mathrm{S}$, , et al. A clinic-based youth development program to reduce sexual risk behaviors among adolescent girls: prime time pilot study. Health Promot Pract 2012 Jul; 13(4):462-71.

[4] Dehne K, Riedner G. sexually transmitted infections among adolescents: the need for adequate health care. Geneva: WHO; $2005 . \quad$ Available from: whqlibdoc.who.int/publications/2005/9241562889.pdf

[5] Reitman DS. Adolescent medicine update: update on sexually transmitted diseases: gonorrhea and Chlamydial infections, 2009; Available from: http://www.consultantlive.com/display/article/10162/ 10971

[6] Hill YL, Biro FM. Adolescents and sexually transmitted infections.CME Feature 2009. Available from: http://www.hawaii.edu/hivandaids/

[7] Mayaud P, Mabey D. Approaches to the control of sexually transmitted infections in developing countries: old problems and modern challenges. Sexual Transmitted Infection. 2004; 80: 174-82.

[8] World Health Organization. Global strategy for the prevention and control of sexually transmitted infections: 2006-2015. Geneva: WHO 2007. Available from: http://www.who.int/reproductivehealth/

[9] Berhane Y, Haile mariam D, Kloos H. Epidemiology and Ecology of Health and Disease in Ethiopia. Ethiopian Journal of Health Development. 2006; 435-474; Addis Ababa, Ethiopia. Available from: ejhd.uib.no/ejhd.../HIV_Bibliography_EJHD_Vol_211HIV_Bibliog.

[10] Tigray Regional Health Bureau (TRHB). Report of STD for 2011/2012 Fiscal year. Mekelle Ethiopia: HAPCO, August 2012

[11] Central StatiSTDcal Agency [Ethiopia] and ICF International. Ethiopia Demographic and Health Survey 2011. Addis Ababa, Ethiopia and Calverton, Maryland, USA: Central Statistical Agency and ICF International, 2012.

[12] Central Statistical Agency [Ethiopia] and ORC Macro. Ethiopia Demographic and Health Survey 2005. Addis Ababa, Ethiopia and Calverton, Maryland, USA: Central Statistical Agency and ORC Macro, 2006.

[13] Ministry of Health Federal Democratic Republic of Ethiopia. Report on Progress towards Implementation of the Declaration of Commitment on HIV/AIDS. Addis Ababa, Ethiopia: HAPCO; August 2012.

[14] Tigray Regional Health Bureau (TRHB). Tigray regional health bureau profile for the 20011/12 EFY. Tigray, Mekelle, 2013.

[15] Bereket Y, Terefe G, Mulat T. Prevalence and Associated Factors of Sexually Transmitted Infections among Students of WolaitaSodo University, Southern Ethiopia; International Journal of Scientific \& Technology Research. 2013; 2(2).

[16] Muluken D, Maereg W. Predictors of consistent condom use among University students: Hierarchical analysis Debre Berhan, Ethiopia; Global Journal of Medicine and Public Health. 2012 July- August; 1(4): 23-28.

[17] Bureau of Statistics, Kampala, Uganda, ICF International Calverton, Maryland, USA. Uganda Demographic and Health Survey 2011 Uganda MEASURE DHS August 2012.

[18] Guttmacher Institute. Adolescents in Ghana Facts in Brief; New York; May 2004.

[19] Ministry of Health, Phnom Penh, Cambodia MEASURE DHS ICF Macro Calverton, Maryland, USA September 2011.

[20] Moges B, Yismaw G, Kassu A, Megabiaw B, Alemu S, et, al,. Sexually transmitted infections based on the syndromic approach in Gondar, BMC Public Health 2013, 13:143. doi:10.1186/1471-2458-13-143

[21] Moore AM., Biddlecom AE. and Zulu EM. Prevalence and meanings of exchange of money or gifts for sex in unmarried adolescent sexual relations hips in sub-Saharan Africa; African Journal of Reproductive Health. 2007 Dec; 11(3): 44-61.

[22] Rajapure V, Tirwa R, Poudyal H, Thakur N. Prevalence and Risk Factors Associated with Sexually Transmitted Diseases (STDs) in Sikkim. Journal of Community Health. 2013 Feb; 38(1):156-162. 
[23] Zelalem A. Prevalence and correlates of multiple sexual partnerships among private college students in Bahirdar city, northwest Ethiopia; Science Journal of Public Health, 2013; 1(1): 9-17.
[24] Mazengia1, Alemayehu W. Age at sexual initiation and factors associated with it among young women in North East Ethiopia; Ethiopian. Ethiopian Journal of Health Development. 2009; 23(2):154-162. 